\title{
Canlı Donörden Böbrek Nakli: İlk Deneyimlerimiz
}

\section{Renal Tranplantation in Living Kidney Donors: First Experiences}

\author{
${ }^{1}$ Necattin FIRAT, ${ }^{2} \mathrm{Hamad}$ DHEIR, ${ }^{3}$ Emrah AKIN, ${ }^{2}$ Savaş SIPAHII, ${ }^{1}$ Fatih ALTINTOPRAK, \\ ${ }^{1}$ Fehmi ÇELEBİ, ${ }^{3}$ Mertcan AKÇAY
}

\author{
${ }^{1}$ Sakarya Üniversitesi Tıp Fakültesi, Genel Cerrahi Anabilim Dalı, Sakarya, Türkiye \\ ${ }^{2}$ Sakarya Üniversitesi Tıp Fakültesi, Nefroloji Bilim Dalı, Sakarya, Türkiye \\ ${ }^{3}$ Sakarya Üniversitesi Eğitim ve Araștırma Hastanesi- Genel Cerrahi Ana Bilim Dalı, Sakarya, \\ Türkiye
}

\begin{abstract}
Necattin Firat: https://orcid.org/0000-0003-0684-8187
Hamad Dheir: https://orcid.org/0000-0002-3569-6269

Emrah AKIN: https://orcid.org/0000-0003-0224-3834

Savaş Sipahi: https://orcid.org/0000-0001-6829-121X

Fatih Altıntoprak: https://orcid.org/0000-0002-3939-8293

Fehmi Çelebi: https://orcid.org/0000-0003-1157-8556

Mertcan Akçay: https://orcid.org/0000-0003-3513-292X
\end{abstract}

ÖZ

Amaç: Son dönem böbrek yetmezliği belirgin morbidite ve mortalite ile toplumda oldukça yaygındır. Böbrek yetmezliği olan hastalarda, yaşam kalitesini ve sağ kalımı arttırdığı için böbrek nakli etkin bir tedavi seçeneğidir. $\mathrm{Bu}$ çalışmanın amacı yeni hizmete giren böbrek nakil merkezindeki ilk sonuçları değerlendirmektir.

Materyal ve Metot: Nisan 2019 ile Ekim 2019 tarihler arasında, Sakarya Üniversitesi Eğitim Araştırma Hastanesi Böbrek Nakil Merkezi'nde böbrek yetmezliği nedeniyle nakil yapılan 20 hasta retrospektif olarak değerlendirildi. Hastaların ve donörlerin demografik özellikleri kaydedildi ve operasyon öncesi ve sonrası laboratuvar sonuçları degerlendirildi. Posttransplantasyon akut komplikasyonlar kaydedildi. Verileri uygun istatistik yöntemi (ortalama \pm standart sapma ve ortanca(min,max)) ile değerlendirildi.

Bulgular: Böbrek alıcıların ortalama yaşı $46,10 \pm 11,52$ y11, Vucut kitle indeksi (VKİ) 27,00 $\pm 6,00$ idi ve \%40' kadın \%60'1 erkekti. Nakil yapılan hastaların operasyon sonras1 ortalama serum kreatinin 1.gün:3,10 $\pm 1,60 \mathrm{mg} / \mathrm{dl}$,

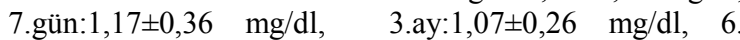
Ay: $1,10 \pm 0,28 \mathrm{mg} / \mathrm{dl}$ idi.

Sonuç: Son dönem böbrek yetmezliği olan hastalığı olan hastalarda yapılan böbrek nakil operasyonu kısa dönem sonuçlarının başarılı olduğu görülmektedir. Laparoskopik donör nefrektomi uygun vericilerde ilk tercih edilmesi gereken yaklaşımdır. Son dönem böbrek yetmezliği olan hastalara mümkün olduğunca böbrek nakli gerçekleștirilmesi hem hasta sağ kalımı hem de ekonomik maliyet açısindan önerilen tedavi yöntemdir.

Anahtar Kelimeler: Böbrek nakli, kronik böbrek yetmezliği, laparoskopik donör nefrektomi

\section{ABSTRACT}

Objective: End-stage renal failure is quite common in the community with pronounced morbidity and mortality. Kidney transplantation is an effective treatment option in patients with renal insufficiency as it improves quality of life and survival. The aim of this study is to evaluate the first results in currently introduced kidney transplant center.

Materials and Methods: Between April 2019 and October 2019, 20 patients who were transplanted due to kidney failure at the Sakarya University Training and Research Hospital Kidney Transplant Center were evaluated retrospectively. The demographic characteristics of the patients and donors were recorded and the laboratory results before and after the operation were evaluated. Acute complications of posttransplantation were recorded. The data were evaluated by appropriate statistical method (overall \pm standard deviation and median (min, max)).

Results: The average age of kidney recipients was $46.10 \pm$ 11.52 years, BMI was $27.00 \pm 6.00$, and $40 \%$ were female and $60 \%$ were male. Average serum creatinine after the operation of patients who were transplanted 1.day: $3.10 \pm$ $1.60 \mathrm{mg} / \mathrm{dl}$, 7.day: $1,17 \pm 0,36 \mathrm{mg} / \mathrm{dl}$, 3.month: $1,07 \pm 0,26 \mathrm{mg} / \mathrm{dl}$, 6 th month: $1,10 \pm 0,28 \mathrm{mg} / \mathrm{dl}$.

Conclusion: The short-term results of kidney transplantation performed in patients with end-stage renal failure appear to be successful. Laparoscopic donor nephrectomy is the first choice approach in appropriate donors. Performing kidney transplantation as much as possible to patients with end-stage renal failure is the recommended treatment method in terms of both patient survival and economic costs.

Keywords : Chronic renal failure, laparoscopic donor nephrectomy, kidney transplant

Yayın Bilgisi / Article Info:

Gönderi Tarihi/ Received: 17/03/2020

Kabul Tarihi/ Accepted: 11/05/2020

Online Yayın Tarihi/ Published: 30/06/2020
Necattin Firat

Sakarya Üniversitesi Tıp Fakültesi, Genel Cerrahi Anabilim Dalı,

Sakarya, Türkiye

Tel: +90 02648884000

Fax: +90 02642759192

E-mail: necattinf@sakarya.edu.tr 
Atıf/ Cited: Fırat N, ve ark. Canlı Donörden Böbrek Nakli: İlk Deneyimlerimiz. Online Türk Sağlık Bilimleri Dergisi 2020;5(2):356-363. doi: $10.26453 /$ otjhs. 705092

\section{GİRIŞ}

Son dönem böbrek hastalığı (SDBH) prevalansı dünya genelinde giderek artmakta ve tüm dünyada sağlık sistemleri için önemli bir sorun teşkil etmektedir. Böbrek nakli (BN), SDBH için tercih edilen en iyi renal replasman tedavi yöntemidir ve başarılı bir $\mathrm{BN}$, hastanın yaşam kalitesini önemli ölçüde arttırmaktadır. Böbrek nakilli hastaların nakil sonrası ciddi immünsupresyona maruz kaldıkları için akut ve kronik komplikasyonlar açısından yakından takip edilmesi gerekmektedir. Bu hastalarda firsatçı enfeksiyonlar, akut rejeksiyonlar, aterosklerotik kardiyovasküler (KVS) olay gelişimi ve uzun dönemde malignite gelişme riski yüksektir. BN olacak hastalar ve donör adayları, donanımlı transplant merkezlerinde deneyimli bir ekip tarafindan titizlikle belirlenip uluslararası rehberlere göre seçilmelidir. $\mathrm{BN}$, diyaliz ile kıyaslandığında daha düşük maliyetlidir ve hastaya daha uzun ve kaliteli bir yaşam sunmaktadır. ${ }^{1,2}$

Diyaliz ihtiyacı olan hasta sayının giderek artması ayrıca kadavra organ temininin yetersiz kalması nedeniyle kadavra bekleme listesi giderek artmaktadır. Bundan dolayı canlı bağışçılardan gerçekleşen nakillerin sayısı da artmaktadır. ${ }^{3}$ Özellikle Laparoskopik donör nefrektominin yapılmaya başlanması ve bunun avantajlarının birçok çalışmada gösterilmesiyle organ vermeye gönüllü canlı bağış̧̧ların sayısı daha da artmıştır. ${ }^{4-6}$ Ayrıca pre-emptif böbrek nakillerin sonuçları kronik diyaliz programında olan hastaların sonuçlarıyla kıyaslandığında çok daha iyi olduğu bildirilmiştir. ${ }^{7}$ Sakarya üniversitesi Eğitim ve Araştırma hastanesi bünyesinde kurulan böbrek nakil merkezimizdeki ilk deneyimlerimizi ve kısa süreli sonuçlarımızı literatürler eşliğinde paylaşmayı amaçladık.

\section{MATERYAL VE METOT}

Sakarya Üniversitesi Tıp Fakültesi Girişimsel Olmayan Etik Kurulu'ndan izin alınmıştır (Tarih: 11/09/2019, karar no: 259). Sakarya Üniversitesi Eğitim ve Araştırma Hastanesi'nde şubat 2019 tarihinde hizmete giren böbrek nakli merkezinde gerçekleştirilen canlı vericili böbrek nakil ameliyatlarının kısa süreli sonuçları retrospektif olarak değerlendirildi.

Çalışmaya SDBH olan ve böbrek nakil konseyinde nakil kararı çıkarak BN yapılan hastalar dahil edildi. Kadavra BN olan hastalar çalışmaya dahil edilmedi.
BN öncesi tüm hastalar nakil konseyinde değerlendirildi ve burada alınan kararlar doğrultusunda operasyonlar gerçekleştirildi. Tüm hastalara kan gurubu uyumlu böbrek nakli yapıldı. Böbrek alıcısı olan hastalara desensitizasyon protokolü olarak indüksiyon (antitimosit globülin) + idame tedavi (steroid+kalsinorin inhibitörü+antiproliferatif ajan) uygulandı. Tüm hastalara antibiyotik profilaksisi için operasyondan bir saat önce $1 \mathrm{gr}$ flk sefazolin sodyum intravenöz olarak uygulandı. Nakil yapılan hastalar ameliyat sonrası yoğun bakım ünitesinde takip edildi ve ameliyat sonras 1 1 . Gün doppler ultrason yapılarak nakil böbrek kan akımı değerlendirildi ve hastalar servise alınd.

Böbrek alıcı ve vericilerin tüm demografik özellikleri ve laboratuvar verileri kaydedildi. Hastaların diyaliz süreleri, renal replasman yöntemi, akut dönem cerrahi ve klinik komplikasyonları, double J kateteri takılıp takılmadığı, hastaneye yatıș süreleri, greft fonksiyonları, kalsinörin inhibitörü ilaçların kandaki seviyeleri, dren çekim tarihleri, renal arter ve ven sayısı, vasküler anastomoz yöntemi, üreter anastomoz yöntemi, primer hastalığı ve komorbid hastalık varlığı bilgileri kaydedildi. Post op 5. Gün idrar sondası çekildi. Tüm hastalara operasyon esnasinda drenaj kateteri kullanıldı ve getireni $30 \mathrm{cc}$ alt1na inince diren çekildi.

Hastaların yaş, vucut kitle indeksi, kreatinin değerleri ve diğer değişkenler basit istatisitik yöntemleri (ortalama \pm standart sapma ve medyan (min,max)) kullanılarak tablolar halinde sunuldu.

\section{BULGULAR}

Böbrek nakli olan hastaların demografik verileri ve serum kreatinin seviyeleri Tablo-1'de gösterildi. Hastaların ortalama yaş1 $46,10 \pm 11,52$ y1l, vucut kitle

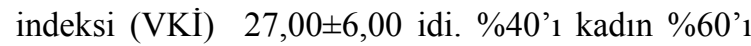
erkekti. Hastaların \%50'si yeni tanı konulan preemptif hastalardı. Diyalize giren hastaların \% 45'i hemodiyaliz, \%5'i periton diyalizi alıyordu. $\mathrm{Bu}$ hastalarda ortanca diyaliz süresi 9 ay (3-96 ay) idi. Primer hastalıkları açısından hastalar değerlendirildiğinde, hastaların $\% 45$ 'i hipertansiyon, $\% 35$ ' $\mathrm{i}$ glomerulonefrit, $\% 5$ 'i diyabet, $\% 5$ 'i böbrek taşı, $\%$ 5'i polikisitik böbrek hastalığ $1, \% 5$ 'i herediter nefrit nedenli son dönem böbrek yetmezliği olduğu görüldü.

İki hastada daha önce böbrek nakli öyküsü vardı. Hiçbir hastada akut cerrahi komplikasyon yaşanma- 
dı. Tüm alıcıların idrarları böbreğin perfüze edilmesiyle hemen gelmeye başladı. Hastaların tümünde eksternal iliak arter renal arter ve eksternal iliak ven renal ven uç-yan anastomozu uyguland. Üreter anastomozunda double $\mathrm{J}$ kateteri kullanılarak üreteroneosistestomi yapıldı.

Nakil sonrası ortalama takip süresi 8 aydı. Operas-

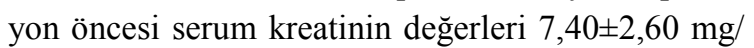
dl idi. Operasyon sonras1 1. gün ortalama serum

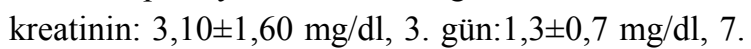
gün: $1,17 \pm 0,36 \mathrm{mg} / \mathrm{dl}, 3$. ay: $1,07 \pm 0,26 \mathrm{mg} / \mathrm{dl}, 6$. Ay $1,10 \pm 0,28$ idi (Tablo-1).

Böbrek vericilerinin demografik verileri ve serum kreatinin seviyeleri Tablo-2' de gösterildi. Vericilerin ortalama yaşı $46,5 \pm 10,47$ y1l ve VKİ $27 \pm 3,8$ idi. Vericilerin \%40’1 kadın \%60’1 erkekti. Tüm canlı verici nefrektomi ameliyatları laporaskopik yöntemle gerçekleştirildi.

Posttransplantasyonda akut komplikasyonlar Tablo3'de gösterildi. Bir hastada (\%5) insizyon hattında koleksiyon, bir hastada (\%5) BK virüsü nefropatisi ve iki hastada (\%10) akut sellüler rejeksiyon saptandı. Komplikasyonların tamamı başarı ile tedavi edildi.

\section{TARTIŞMA VE SONUÇ}

Son dönem böbrek yetmezliği olan hastalarda yap1lacak olan böbrek nakli alternatif tedavilerle kıyaslandığında hasta sağ kalımı için daha avantajlıdır ve maliyeti daha düşüktür.

Başarılı bir BN operasyonunun en önemli göstergesi greft sağ kalımıdır. Bir yıllık greft sağkalımı ile ilgili litaratürde (\%83.2-\%96.8) farklı bilgiler vardır. ${ }^{8,9}$ Greft sağ kalımında cerrahi komplikasyonlar, enfeksiyonlar, HLA uyumu, vericinin yaşı, hastanın daha önce diyaliz alması, uygulanan tedavi protokolleri, immunsüpresif ilaçlara ulaşım, immun riskli nakillerde desensitizasyon işlemleri, böbrek yetmezliğine neden olan primer hastalık gibi bir çok neden etkili olabilmektedir. BN olan hastaların ortalama 8 aylık yapılan takiplerinde greft sağ kalım oranı \% 100 idi. Greft kaybına neden olan cerrahi komplikasyonlar daha çok erken dönemde görülmektedir. Hematom, renal arter ve renal ven trombozu, renal arter stenozu, üreter darlığı, idrar kaçağı ve lenfosel en önemli cerrahi komplikasyonları oluşturmaktadır. Hastalarımızın hiçbirinde bu tür komplikasyon görülmedi.

Böbrek naklinden sonraki ilk bir yıl içindeki morbiditede enfeksiyonların önemli bir yeri vardır. ${ }^{10,11}$ Ameliyat sonrası cerrahi alan enfeksiyonu özellikle obez hastalarda görülebilir. Morbid obez olan bir hastamızda (VKI 38 idi) yara yeri enfeksiyonu görüldü. Yara yeri kültüründe gram negatif bakteri üredi. Perkütan direnaj ve antibiyotik tedavisi ile enfeksiyon tamamen geriledi. Böbrek nakli sonrası üriner enfeksiyonlar da sık görülmektedir. ${ }^{12}$ İmmunsüpresif ilaçlar ve üreter anastomozu nedeniyle konulan double J kateteri üriner enfeksiyonların artmasına neden olabilmektedir. Özellikle BK virüs enfeksiyonları greft kaybına neden olabilmektedir. Bir hastamızda $\mathrm{BK}$ virüse bağlı nefropati, bir hastamızda idrar yolu enfeksiyonu saptandı. Bu veriler literatürde bildirilen oranlara göre daha az sıklıkta olduğu saptandı.

HLA uyumunun da greft sağkalımını arttırdığı belirtilmektedir. ${ }^{13}$ En uygun vericiler HLA uyumu tam olan kardeşler arası yapılan nakillerdir. Bizim hastalarımızda HLA uyumu ortanca bir haplotip missmatch olacak şekildeydi.

Preemptif nakillerin diyaliz gören hastaya kıyasla greft ve hasta sağkalım oranı için üstün sonuçları olduğu bildirilmiştir. ${ }^{14}$ Fakat bazı çalışmalarda Preemptif böbrek nakli ile preemptif olmayan nakiller arasında greft sağkalım oranında anlamlı bir fark tesbit edilmemiştir.9 Bizim hastalarımızın \%50'si preemtif nakil \%50'si diyaliz gören hastalardaki nakildi. Bu iki transplant şekli arasındaki kısa süreli sonuçlarda istatistiksel olarak anlamlı fark saptanmad1.

Greft sağkalımı üzerinde dönör yaşının da önemli bir etkiye sahip olduğu iyi bilinmektedir. ${ }^{15,16}$ Bizim çalışmamızdaki verici yaş ortalaması 46,5 $\pm 10,47$ yıl olup genç donörlerden oluşmuştur. Biz bunun donör ve greft sağ kalımı üzerinde olumlu bir etki sağlamasını bekliyoruz.

Eşler arasındaki nakiller, gebelik öyküsü ve HLA uyumsuzluğu akut rejeksiyon için yüksek risk faktörü teşkil etmektedir. ${ }^{17}$ Özellikle kocadan yapılan nakillerde rejeksiyon riski artmaktadır. Nakil yapılan hastalardan 5'i eşler arası nakildi. Bunlardan 2'si kocadan kadina yapılan nakildi. Bu hastalarda akut rejeksiyon ve gecikmiş greft fonksiyonu yaşanmadı. Böbrek naklinde mikofenolat mofetil ve Calsinorin inhibitörleri gibi immunsüpresifler kullanılmaya başladıktan sonra kısa ve uzun dönem greft sağkalımı artmaya başladı. ${ }^{18-20} \mathrm{Bu}$ protokole basiliximab ekleyerek daha iyi sonuç aldığını belirten çalışmalar da mevcuttur. ${ }^{9}$ Biz tavşan kökenli antitimusit globulin ile indüksiyon tedavisi sonrası kalsinorin inhibitörleri, antiproliferatif ajanlar ve kortikosteroid ile idame tedavisi uyguladık. Erken dönem akut rejeksiyon oranlarımız literatür verilerine benzerdi. 
Double j kateterinin böbrek nakli olan hastalarda kullanımı tartışmalıdır. Katater kullanılmasını önermeyenler kateterin kalsifikasyon ve artmış idrar yolu enfeksiyonuna neden olduğunu ve dokunun içine gömülebileceğini bildirilmişlerdir. ${ }^{21,22}$ Katater kullanımını destekleyen çalışmalar kataterin idrar kaçağını ve erken postoperatif tıkanma oranlarını azalttığ $\breve{1}_{-}$ nı ve bu nedenle uzun süreli izlemde daha az cerrahi revizyon gerektirdiğini belirtmişlerdir. ${ }^{9}$ Biz üreter anastomozunda rutin olarak double J katederi kullandık ve yaklaşık 3 hafta sonra katateri çıkardık. Double J kataterle ilgili herhangi bir sorun yaşanmadi.

Özetle, renal replasman tedavilerinde böbrek nakli en iyi tedavi metodudur. Yeterli donanıma sahip merkezlerde bu tür operasyonların yapılması hasta sağ kalımı ve maliyet yükü açısından büyük avantaj sağlamaktadır. Merkezimizde böbrek nakli olan hastalarla ilgili kısa süreli sonuçlarımız ulusal ve uluslararası sonuçlarla paralel hatta komplikasyonlar açısından daha düşük orandadır.

Etik Komite Onayı: Çalışmamız Sakarya Üniversitesi Tıp Fakültesi Girişimsel Olmayan Klinik Araştırmalar Etik Kurulu (Tarih: 11/09/2019, karar no: 259) tarafindan onayland1.

Çıkar Çatışması: Yazarlar, bu makalenin araştırılması, yazarlığı ve / veya yayınlanması ile ilgili olarak potansiyel çıkar çatışması bildirmemişlerdir.

Yazar Katkıları: Fikir - NF, HD; Denetleme - FÇ, SS; Malzemeler - NF, HD, EA, FA; Veri toplanmas1 ve işlemesi - NF, MA; Analiz ve yorum - NF, HD; Yazıyı yazan - NF, H.D.

Hakem değerlendirmesi: D1ş bağımsız.

Teşekkür: Prof. Dr. Mehmet Akif Çakar ve organ nakli koordinatörü Gülercan Şenel'e, daha önce yayınlanmamış çalışmayla ilgili ek verileri sağladıkları için teşekkür ediyoruz.

\section{KAYNAKLAR}

1. Arogundade FA, Abd-Essamie MA, Barsoum RS. Health-related quality of life in emotionally related kidney transplantation: deductions from a comparative study. Saudi J Kidney Dis Transpl. 2005;16(3):311-320.

2. Garcia Garcia G, Harden P, Chapman J. The global role of kidney transplantation. Arab J Nephrol Transplant. 2012;81(5):425-427. doi:10.1097/MOT.0b013e328354c277

3. Tullius SG, Rabb H. Improving the supply and quality of deceased-donor organs for transplantation. N Engl J Med. 2018;378
(20):1920-1929. doi:10.1056/NEJMra1507080

4. Brown SL, Biehl TR, Rawlins MC, Hefty TR. Laparoscopic live donor nephrectomy: A comparison with the conventional open approach. J Urol. 2001;165(3):766-769. doi:10.1016/S0022-5347(05)66521-4

5. Flowers JL, Jacobs S, Cho E, et al. Comparison of open and laparoscopic live donor nephrectomy. Ann Surg. 1997;226(4):483-489. doi:10.1097/00000658-199710000-00009

6. Hiller J, Sroka M, Holochek MJ, Morrison A, Kavoussi LR, Ratner LE. Functional advantages of laparoscopic live-donor nephrectomy compared with conventional open-donor nephrectomy. J Transpl Coord. 1997;7(3):134140. doi:10.7182/prtr.1.7.3.v503420j4hr31621

7. Arze Aimaretti L, Arze S. Preemptive Renal Transplantation - The Best Treatment Option for Terminal Chronic Renal Failure. Transplant Proc. 2016;48(2):609-611. doi:10.1016/ j.transproceed.2016.02.047

8. Arogundade FA. Kidney transplantation in a low -resource setting: Nigeria experience. Kidney Int Suppl. 2013;3(2):241-245. doi:10.1038/ kisup. 2013.23

9. Tasaki M, Saito K, Nakagawa Y, et al. 20-year analysis of kidney transplantation: A single center in Japan. Transplant Proc. 2014;46(2):437 -441. doi:10.1016/j.transproceed.2013.10.052

10. Kinnunen S, Karhapää P, Juutilainen A, Finne P, Helanterä I. Secular trends in infection-related mortality after kidney transplantation. Clin J Am Soc Nephrol. 2018;13(5):755-762. doi:10.2215/ CJN.11511017

11. Yalci A, Celebi ZK, Ozbas B, et al. Evaluation of Infectious Complications in the First Year after Kidney Transplantation. Transplant Proc. 2015;47(5):1429-1432. doi:10.1016/ j.transproceed.2015.04.056

12. Harris AD, Fleming B, Bromberg JS, et al. Surgical Site Infection after Renal Transplantation. Infect Control Hosp Epidemiol. 2015;36(4):417-423. doi:10.1017/ice.2014.77

13. Takemoto S, Port FK, Claas FHJ, Duquesnoy RJ. HLA matching for kidney transplantation. Hum Immunol. 2004;65(12):1489-1505. doi:10.1016/ j.humimm.2004.06.008

14. Roake JA, Cahill AP, Gray CM, Gray DWR, Morris PJ. Preemptive cadaveric renal transplantation - Clinical outcome. Transplantation. 1996;62(10):1411-1416. doi:10.1097/00007890-199611270-00006 
15. Lim WH, Clayton P, Wong G, et al. Outcomes of kidney transplantation from older living donors. Transplantation. 2013;95(1):106-113. doi: 10.1097/TP.0b013e318277b2be

16. Noppakun K, Cosio FG, Dean PG, Taler SJ, Wauters R, Grande JP. Living donor age and kidney transplant outcomes. Am J Transplant. 2011;11(6):1279-1286. doi: 10.1111/j.16006143.2011.03552.x

17. Ghafari A. Offspring-to-Mother and Husband-toWife Renal Transplantation: A Single-Center Experience. Transplant Proc. 2008;40(1):140142. doi: 10.1016/j.transproceed.2007.11.062

18. Calne RY, Thiru S, McMaster $\mathrm{P}$, et al. Cyclosporin a in patients receiving renal allografts from cadaver donors. J Am Soc Nephrol. 1998;9(9):1751-1756. doi: 10.1016/ S0140-6736(78)91970-0

19. Jensik SC. Tacrolimus (FK 506) in kidney transplantation: Three-year survival results of the US Multicenter, randomized, comparative trial. Transplant Proc. 1998;30(4):1216-1218. doi: 10.1016/S0041-1345(98)00216-4

20. Sollinger HW, Deierhoi MH, Belzer FO, Diethelm AG, Kauffman RS. Rs-61443 - a phase $i$ clinical trial and pilot rescue study. Transplantation. 1992;53(2):428-432. doi: 10.1097/00007890-199202010-00031

21. Dominguez J, Clase CM, Mahalati K, et al. Is routine ureteric stenting needed in kidney transplantation? A randomized trial. Transplantation. 2000;70(4):597-601. doi: 10.1097/00007890-200008270-00011

22. Sözen H, Özen O, Fidan K, Söylemezoğlu O, Dalgıç A. Outcome of the Double-J Stent Placement in Pediatric Kidney Transplant: A Single Center Experience. Exp Clin Transplant. 2017;1(1):1. doi: 10.6002/ect.2016.0280 
Tablo 1. Böbrek alıcı hasta demografik veriler ve kreatinin değerleri.

\begin{tabular}{|c|c|c|c|}
\hline & Kadın & Erkek & Toplam \\
\hline Say1 (n) & 8 & 12 & 20 \\
\hline Yaş (y1l) & $49,87 \pm 9,83^{*}$ & $43,58 \pm 12,27$ & $46,10 \pm 11,52$ \\
\hline Diyaliz süresi (ay) & $9(3-9) * *$ & $9(3-96)$ & $9(3-96)$ \\
\hline Preemptif nakil oranı (\%) & $\% 30$ & $\% 20$ & $\% 50$ \\
\hline HLA-uyumu (missmatch) & $2,5(0-6)$ & $3,5(0-6)$ & $3(0-6)$ \\
\hline Vki (kg/m2) & $27,44 \pm 4,91$ & $26,23 \pm 5,09$ & $27,00 \pm 6,00$ \\
\hline Preop kreatinin (mg/dl) & $5,20 \pm 1,29$ & $8,80 \pm 2,33$ & $7,40 \pm 2,60$ \\
\hline Postop 1. gün kreatinin(mg/dl) & $2,10 \pm 0,66$ & $3,80 \pm 1,70$ & $3,10 \pm 1,60$ \\
\hline Postop 7. Gün kreatinin(mg/dl) & $1,10 \pm 0,43$ & $1,20 \pm 0,32$ & $1,17 \pm 0,36$ \\
\hline Postop 3. Ay kreatinin(mg/dl) & $0,96 \pm 0,21$ & $1,15 \pm 0,26$ & $1,07 \pm 0,26$ \\
\hline Postop 6. Ay kreatinin(mg/dl) & $0,93 \pm 0,23$ & $1,21 \pm 0,26$ & $1,10 \pm 0,28$ \\
\hline
\end{tabular}

*. Ortalama \pm Standart sapma; ** Ortanca (min-max). 
Tablo 2. Böbrek verici hasta demografik veriler ve kreatinin değerleri.

\begin{tabular}{|l|c|c|c|}
\hline & Kadın & Erkek & Toplam \\
\hline Sayı (n) & 8 & 12 & 20 \\
\hline Yaş (yıl) & $47,75 \pm 7,62^{*}$ & $45,66 \pm 12,27$ & $46,50 \pm 10,47$ \\
\hline Vki (kg/m2) & $29,64 \pm 3,16$ & $25,49 \pm 4,26$ & $27,36 \pm 4,00$ \\
\hline Preop kreatinin (mg/dl) & $0,57 \pm 0,09$ & $0,78 \pm 0,11$ & $0,70 \pm 0,10$ \\
\hline Postop 1. gün kreatinin(mg/dl) & $0,89 \pm 0,11$ & $1,23 \pm 0,21$ & $1,10 \pm 0,20$ \\
\hline Postop 6. Ay kreatinin(mg/dl) & $0,9 \pm 0,14$ & $1,20 \pm 0,20$ & $1,10 \pm 0,20$ \\
\hline
\end{tabular}

*: Ortalama \pm Standart sapma. 
Tablo 3. Posttransplantasyonda akut komplikasyonlar.

\begin{tabular}{|l|l|}
\hline Özellik & Sonuç \\
\hline Kanama (\%) & $\% 0$ \\
\hline Akut rejeksiyon (\%) & $\% 10$ \\
\hline Gecikmiş Greft Fonksiyonu (\%) & $\% 0$ \\
\hline İdrar Kaçağı (\%) & $\% 0$ \\
\hline Lenfosel (\%) & $\% 0$ \\
\hline Reoperasyon (\%) & $\% 0$ \\
\hline İdrar yolu enfeksiyonu (\%) & $\% 5$ \\
\hline Sitomegalovirus Enfeksiyonu (\%) & $\% 0$ \\
\hline Polyoma Virusu Nefropati (\%) & $\% 5$ \\
\hline
\end{tabular}

